\title{
NEEDS AND SOURCES OF INFORMATION ON DISEASE MANAGEMENT FOR PARENTS OF CHILDREN WITH DIABETES MELLITUS
}

\author{
Indrè Čergelytė - Podgrušienè \\ Mykolas Romeris university, Lithuania \\ Vida Gudžinskienè \\ Mykolas Romeris university, Lithuania
}

\begin{abstract}
Type 1 diabetes mellitus in children alters the rhythm and daily routines of children and parents, as there appears a need to treat and control this disease. Parents need to learn how to optimally care for the health of their children: monitor levels of blood glucose, follow a diet plan, inject insulin and organize the child's schedule. Research object: needs and sources of information for parents of children with diabetes mellitus on the management of their child's disease. Research aim is to reveal the needs and sources of information on the disease and its management for parents of children with diabetes mellitus. Research tasks: 1) to identify the needs of parents of children with diabetes mellitus for information on the disease management; 2) to reveal how and in what ways parents search for information on the child's disease and its management. Research methods: theoretical - analysis, generalization and systematization of scientific literature; empirical - a semi-structured method of interview has been used for the collection of data; method of content analysis has been applied to the study of research data. There were 6 women of children with diabetes mellitus, who agreed to participate in the research. Participants of the research raise children who have diabetes mellitus up to 3 years after diagnosis; children's age ranges from 3 to 11 years old. All women had higher education. The empirical study revealed that mothers of children with diabetes mellitus require information on the child's disease and its control. Participants of the research mentioned that they try to obtain information from various sources: medical institutions, relatives, the Internet, social networks, etc.
\end{abstract}

Keywords: disease management, needs and sources of information. parents, type 1 diabetes.

\section{Introduction}

Diabetes mellitus in children is a chronic disease that radically changes the life of the child and one's family (Schiaffini, Carducci, Cianfarani, Mauti, \& Nicolais, 2019). It has been noted that type 1 diabetes is a disease when pancreas stops producing insulin; in a child insulin is usually stopped being produced because of a defect in the immune system, and the immune system begins to destroy the pancreas (International Diabetes Federation, 2019). 
Čergelytè - Podgrušiene \& Gudžinskienè, 2020. Needs and Sources of Information on Disease Management for Parents of Children with Diabetes Mellitus

One of the main tendencies of diabetes mellitus in children is the complications of the disease that can occur immediately after the onset or sometime after the diagnosis (Coppola, Luzi, Montalcini, Giustina, \& Gazzaruso, 2018; Weng, Zachariae, Christensen, Svensson, \& Berg, 2019; Yilmaz et al., 2019). Not only does diabetes mellitus damage the endocrine system and various organs, but also causes failures in the organism (Žilinskienè, Šinkariova, \& Perminas, 2007; Kadhim, Al-farari, \& Mafer, 2019). When type 1 diabetes mellitus occurs in a child, one feels debilitated and apathetic; still, the Society for Paediatric Endocrinology (2017) emphasizes key symptoms that are characteristic at the onset of the disease: excessive thirst, increased urination, weight loss, increased appetite, drowsiness, lack of energy, loss of focus, vomiting and stomach pains, as well as impaired vision. Thus it is important that a child with diabetes mellitus and one's parents would receive necessary information about this disease, its symptoms and management, control, and possible complications.

Parents need to be well aware of diabetes mellitus in order to achieve the optimal health for their child and help one accept and control this disease (Povey \& Clark - Carter, 2007; Prikken et al., 2019; Čergelytė - Podgrušienè \& Gudžinskienė, 2019). K. Lange, P. Swift, E. Pankowska, T. Danne (2014) highlight that parents and children require health knowledge and skills: how to properly check blood glucose levels, how to properly inject insulin, what food products to choose, how to control the disease at home and at school, as well as learn to organize one's schedule. It is noted that parents of children with diabetes mellitus also require psychological preparation: parents' acceptance of the disease, coping with stress and ability to adapt to changes; thus, it is important to develop the child's sense of responsibility and skills of self-control (Phelan et al., 2018; Schiaffini, Carducci, Cianfarani, \& Mauti, 2019; Law, Fisher, Eccleston, \& Palermo, 2019).

Research object: needs and sources of information for parents of children with diabetes mellitus on the management of the child's disease.

Research aim is to reveal the needs for information on the management of diabetes and sources of information on this disease and its management for parents of children with this diabetes mellitus.

Research tasks:

1. To identify the needs of parents of children with diabetes mellitus for information on the disease management;

2. To reveal how and in what ways parents search for information on the child's disease and its management.

Research methods: theoretical - analysis, comparison, generalization and systematization of scientific literature and documents; empirical - a semistructured method of interview has been used for the collection of data; method of content analysis has been applied to the study of research data. 
Research questions:

1. What health knowledge and skills were necessary at the onset of the disease?

2. What health knowledge did they acquire?

3. What were the sources of information?

\section{Research methodology}

Research methods. Qualitative research was chosen for the study. According to Žydžiūnaite \& Sabaliauskas (2017), the purpose of a qualitative study is to research how parents of children with diabetes mellitus adapt to the their child's disease, what encourages them to acquire new knowledge and skills, and what are the main sources of information about the disease. In the study, the method of a semi-structured interview was used. The following article overviews problematic questions of the study: What health knowledge and skills were necessary at the onset of the disease? What health knowledge did they acquire? What were the sources of information? The obtained data were analysed by using the content analysis method. The qualitative content analysis was performed in the following sequence: the repeated reading of the content of transcribed interview texts, the distinction of meaningful elements in the text analysed, the grouping of the distinguished meaningful elements into categories and subcategories, integration of the categories/sub-categories into the context of the phenomenon analysed and the description of their analysis (Žydžiūnaite et al., 2017). P. Mayring (2000) points out that content analysis is a valid method that allows to draw specific conclusions based on the analysed text.

The sample of the research. A criteria-based sample was used in the study. The informants were chosen according to the following criteria: 1) parents of children with diabetes mellitus under 17 years of age; 2) parents of children with diabetes mellitus duration of up to 3 years. The study was conducted in the period of January - May of 2019 in primary schools. The interview lasted from 40 to 70 minutes. There were 6 mothers of children with diabetes mellitus who participated in the qualitative study. Participants of the research have children with diabetes mellitus up to 3 years after diagnosis, the age of children ranges from 3 to 13 years old. All women had higher education.

Ethics of the research. Personal permission of the informants to take part in the research was sought. The researchers obliged themselves to the research participants not to divulge the information related to the organisation and the informant. The principles of anonymity, volunteerism and benevolence were followed. Parents of children with diabetes mellitus were acquainted with the goal of the research, the interview questions, and the importance of a reasoned reflection on their experience. All participants of the research agreed for the 
Čergelytè - Podgrušiene \& Gudžinskienè, 2020. Needs and Sources of Information on Disease Management for Parents of Children with Diabetes Mellitus

interview to be recorded. For confidentiality and anonymity reasons, Roman numerals - I, II, III, IV, V, VI were used to denote informants.

\section{Analysis of research results}

\section{Needs of parents of children with diabetes mellitus for information on the disease management}

Diabetes mellitus is a chronic disease that changes the life of a child and one's family, they have to give up daily habits and change them (Rawdon, Gallagher, Glacken, Swallow, \& Lambert, 2019). When diabetes mellitus occurs in a child, parents experience a variety of feelings (fear, confusion, anxiety) and have to learn themselves, help the child acquire knowledge how to control and manage this disease (Van Gampelaere et al., 2018; Grossoehme et al., 2019). It should be noted that at the onset of diabetes, parents do not have necessary knowledge about this disease, do not know how to manage it and avoid complications.

In order to reveal the needs of parents of children with diabetes mellitus for information on the management of the disease, informants were asked: "What health knowledge and skills did/do you require?”.

According to the experiences of parents of children with diabetes mellitus, the following needs for information on the disease management were identified: general information on diabetes mellitus (kind of a disease, its consequences and treatment plan), information on how to manage and control the disease, how to avoid imminent complications, information on a healthy diet and injection of insulin (Figure 1).

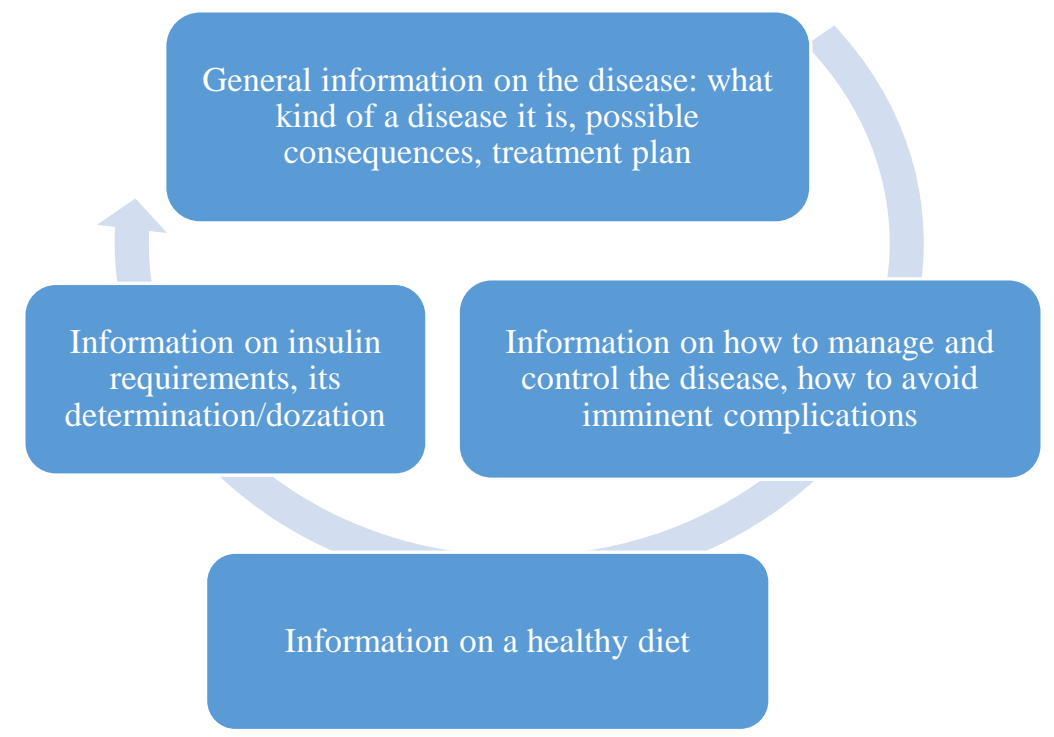

Figure 1 Needs of parents of children with diabetes mellitus for information on the disease management 
The analysis of the informants' responses revealed that at the onset of the disease parents of children with diabetes mellitus required general information on diabetes mellitus (what kind of a disease it is, its consequences and treatment plan - “...we had to know everything... everything... because you can't imagine what kind of a disease it is... nor how that sugar changes, what influences it, what insulin in general is, how much to inject... we didn't know anything..." (II), "...oh, we knew nothing at the beginning of the disease... what is diabetes? ... what happens next... we needed that information and much of it... different information..." (V). Study participants also emphasized that when their child was diagnosed with diabetes mellitus, they required information on how to manage and control the disease in order to avoid imminent complications - “... I absorb information as much as I can... I need information about how to manage the disease... how to control it, I need to pass information to my daughter... for her to understand in future what diabetes mellitus is... how to control it..." (VI), "...basically it is the control and management of the disease, as they determine how the child will live..." (I). Scientists (Rawdon et al., 2019) point out that the management of the disease is primarily the responsibility of parents, which is gradually passed on to the growing child; thus, it is very important to provide the parents with skills of the disease management at its onset.

Informants also stressed that at the onset of the disease they required information on the healthy diet - "...you had to know some things... about carbs... I just can't get to the bottom of them..." (IV), "I think that healthy diet... is the most important thing, as it's somewhat viscous..." (I). In addition, informants emphasized the need for information on insulin dosage: "I don't know how much insulin a child requires, as how much insulin is needed and how to calculate it is very important..." (VI), "mmm, maybe about the same determination of insulin... in terms of carbs and the like... if you eat food - carbs with fats... you should count differently...” (III). Scientists (Albanyan, Albanyan, Adel, \& Zaiton, 2018) note that at the onset of the disease parents suffer from ignorance and lack of information (there is a lot they do not know and understand); thus, it is important to give trainings and provide necessary health knowledge and skills. At the onset of the disease, when the child is diagnosed with diabetes mellitus, parents must adapt to the disease and get accustomed to it. Therefore, it is very important to convey the necessary information in a targeted and clear manner: "At the very beginning, it is simply a chaos, when you don't understand anything..." (II). Information should be provided to parents of children with diabetes mellitus about the management and control of the disease.

Having summarized the responses of informants who participated in the research, it is possible to claim that parents, whose children were diagnosed with diabetes mellitus, required information about the disease and how to control it. The research revealed that parents were surrounded by obscurity, as they did not 
Čergelytè - Podgrušiene \& Gudžinskienè, 2020. Needs and Sources of Information on Disease Management for Parents of Children with Diabetes Mellitus

know what kind of a disease diabetes mellitus is, how it can be treated, and how it would affect the child and one's life.

\section{Sources of information on the disease management for parents of children with diabetes mellitus}

Diabetes mellitus is a disease that requires a constant search for information on its treatment and control and a constant learning and renewal of existing knowledge (Bechara et al., 2018). Scientists (Lee \& Dubovi, 2019) emphasize that parents of children with diabetes mellitus tend to search for information.

In order to reveal sources of information for parents of children with diabetes mellitus on the disease management (where necessary information is acquired from), informants were asked: "Where did you get necessary information about the DM?”. Data analysis allowed to divide sources of information into 3 groups (Figure 2).

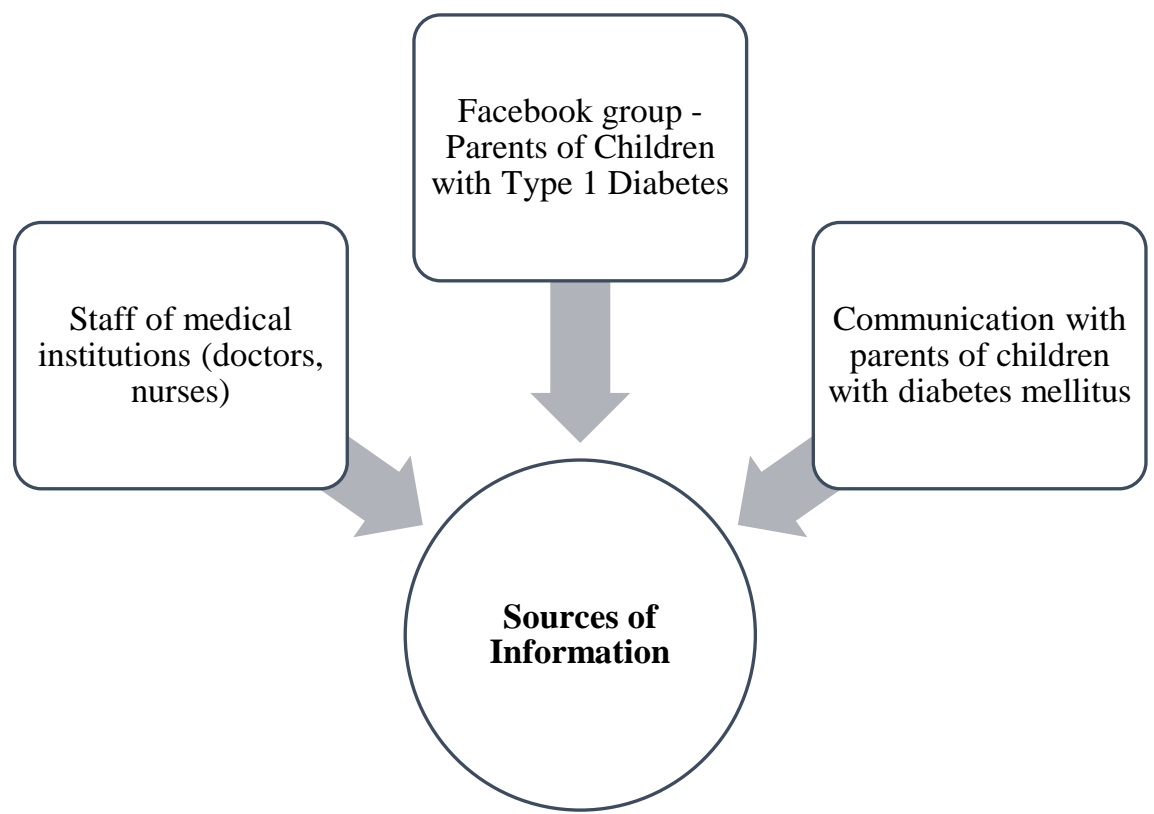

Figure 2 Sources of information on the disease management

Most of participants of the research mentioned that they received information about the disease management from the staff of medical institutions (doctors and nurses) - “...we were admitted to Kaunas hospital... we were there for 2 weeks... there were trainings what insulin does... so most of information we received from the nurse... and the doctor" (II), "...the hospital, the doctor were great... there was a lot of information, there were books and lessons... anyway, there was sufficient information... but you still need it..." (V), "...we receive much information from the doctor, as I have mentioned that we live in Germany..." (III). Researchers (Goethals et al., 2017) point out that medical staff should be 
attentive to parents of children with diabetes mellitus, because the more information parents acquire, the better is the control of the disease. Other participants of the research mentioned that they searched for information in the Facebook group ("Vaiku su I tipo diabetu tevai", English: Parents of Children with Type I diabetes) - “...It's really the Internet... all of those groups...” (I), “... first of all, it's Facebook...ehm... Facebook groups, most of information is there..." (II), “... there is a group in Facebook, it's like a family... if you have a question, you write there and you get an answer..." (IV), "Facebook, I didn't have one, but because of the child's disease, I have created an account because of that group, to get the information I needed..." (V). Participants of the research also stated that their main sources of information about the management of the disease are other parents of children with diabetes mellitus - “...parents, as we learned from them that there are pumps and they told us to put them as fast as we can in order not to torture the child..." (I), “... I talked to my friends and she recommended a woman, whose child has diabetes mellitus for 7 years, so I talked to her..." (III), "...parents, because you share experiences and learn a lot..." (VI). One of the key aspects of acquiring information is social support and social communication, when parents comfort and interact with other parents, who raise children with diabetes mellitus, so there is mutual learning (Boman, 2018). Information about the child's disease and its management helps parents feel safer and more confident: "When you have information, you feel stronger and safer, you feel braver and don't panic..." (V), not only does knowledge help parents to feel safer, but also enables them to reassure their children: "when I see that the child is worried, concerned, knowledge helps me encourage the child, give advice on the basis of advice I received from other parents" (II). Therefore, sufficient amount of information received from doctors, nurses, as well as cooperation and exchange of information with other parents, help both parents of children with diabetes mellitus and the children to live a qualitative life to the full.

Having summarized the experiences of the research informants, it can be seen that parents of children with diabetes mellitus receive information on the management of the disease from the staff of medical institutions (doctors, nurses), Facebook group (Parents of Children with Type 1 Diabetes) and share experiences with other parents of children with the same disease. The research revealed that parents willingly search for information on the child's disease from a variety of sources, because they want to learn as much as possible about the child's disease and want to learn to control it and ensure the quality of life of their children.

\section{Conclusions}

Parents of children with diabetes mellitus, who participated in the research, emphasized that at the onset of the disease, when they became aware of the child's 
Čergelytè - Podgrušiene \& Gudžinskienè, 2020. Needs and Sources of Information on Disease Management for Parents of Children with Diabetes Mellitus

disease, they lacked information on diabetes mellitus, its control, healthy diet and use of insulin.

The research revealed that parents of children with diabetes mellitus receive information on the management of the disease from the staff of medical institutions (doctors, nurses), Facebook group - Parents of Children with Type 1 Diabetes, and share experiences with other parents of children with the same disease. Parents want to have as much knowledge and skills as possible about how to properly manage the disease, in order to maintain the child's optimal health and ensure one's quality of life.

\section{Limitations}

The research is, first of all, limited to subjectivity; it does not seek to present objective truth, but to reveal subjective experiences of research participants that are expected to universally reflect the experiences of other parents of children with diabetes mellitus. The participation of mothers only, without fathers (men), can be also seen as a limitation, as the research reflects the experiences of mothers, their insights and feelings. It may follow that the experiences of the participants do not reveal the experiences of a family that consists of two parents. Another limitation of the research is defined in the sample of participants: experiences of participants may reflect only that of parents, whose children were diagnosed not more than three years ago (that was the benchmark - not earlier, not more than three years ago for the parents to remember the adaptive period). The results of the research may reflect the experiences of parents, whose children were affected by diabetes mellitus earlier, but do not seek to develop the aim by comparing the availability of sources by information technologies and recognize it as a limitation. Due to the chosen methodology (research data saturation principle) the size of the sample is quite small (6 participants) and accordingly, the depth of experiences and reoccurrence seek universal insights, possibly reflecting the experiences of other parents living in the same area (Lithuania), during the same period of time and raising children with diabetes mellitus.

\section{References}

Albanyan, N., Albanyan, A., Adel, A., \& Zaiton, M. (2018). Parental Knowledge and Attitudes Toward Diabetes Mellitus Type 1: A Cross Sectional Study. Europian society for pediatric endocrinology, 89, $110-119$.

Bechara, G.M., Castelo Branco, F., Rodrigues, A.L., Chinnici, D., Chaney, D., Calliari, L.E.P., \& Franco, D.R. (2018). "KiDS and Diabetes in Schools" project: Experience with an international educational intervention among parents and school professionals. Pediatric diabetes, 19(4), 756-760. 
Boman, A. (2017). Learning by supporting others-experienced parents' development process when supporting other parents with a child with type 1 diabetes. Clinical nursing, 21, 5659.

Coppola, A., Luzi, L., Montalcini, T., Giustina, A., \& Gazzaruso, C. (2018). Role of structured individual patient education in the prevention of vascular complications in newly diagnosed type 2 diabetes: the Individual Therapeutic Education in Newly Diagnosed type 2 diabetes (INTEND) randomized controlled trial. Primary care, 60(1), 46 - 49.

Čergelytė -Podgrušienè, I., \& Gudžinskienè, V. (2019). Tèvų, auginančių cukriniu diabetu sergantị vaiką, emocinè būklè ir mokymosi susigyventi su liga patirtis. Socialinis darbas, 17(1), $70-83$

Goethals, E.R., Oris, L., Soenens, B., Berg, C.A., Prikken, S., Van Broeck, N., Weets, I., Casteels, K., \& Luyckx, K. (2017). Parenting and Treatment Adherence in Type 1 Diabetes Throughout Adolescence and Emerging Adulthood. Pediatric Psychology, 42(9), $922-932$.

Grossoehme, D.H, Smith, E., Standiford, D., Morwessele, N., Kichler, J., Maahs, D., Driscoll, K.A., \& Seid, M. (2019). Understanding adolescent and parent acceptability and feasibility experience in a large Type 1 diabetes mellitus behavioural trial. Diabetic medicine, 6, 1- 8.

International Diabetes Federation (2019). IDF Diabetes atlas (nin edition).Brussels: Belgium.

Kadhim, N.Q., Al-farari, S.M.H., \& Maher, F.T. (2019). Study of topoisomerase I (Topo I) level and some biochemical parameters in diabetic patients. EurAsian journal of BioSciences, 13, 517 - 522.

Lange, K., Swift, P., Pankowska, E., \& Danne, T. (2014). Diabetes education in children and adolescents. Pediatric Diabetes, 15(20), 77 - 85.

Law, E., Fisher, E., Eccleston, C., \& Palermo, T. (2019). Psychological interventions for parents of children and adolescents with chronic illness. The Cochrane collaboration, 18(3) $123-126$.

Lee, V.R., \& Dubovi, I. (2019). At Home With Data: Family Engagements With Data Involved in Type 1 Diabetes Management. Journal of the learning sciences, 25, 11 - 31.

Mayring, P. (2000). Retirement as crisis or good fortune? Results of a quantitative-qualitative longitudinal study. Gerontol geriat, 33(2), $124-133$.

Phelan, H., Lange, K., Cengiz, E., Gallego, P., Majaliwa, E., Pelicand, J., Smart, C., \& Hofer, S.E. (2018). ISPAD Clinical Practice Consensus Guidelines 2018: Diabetes education in children and adolescents. Pediatric diabetes, 19, 75-83.

Povey, R.C., \& Clark - Carter, D. (2007). Diabetes and healthy eating: a systematic review of the literature. Sage journal, 33(6), 931- 959.

Prikken, S., Raymaekers, K., Oris, L., Rassart, J. Weets, I., Moons, P., \& Luyckx, K. (2019). A triadic perspective on control perceptions in youth with type 1 diabetes and their parents: Associations with treatment adherence and glycemic control. Diabetes research and clinical practice, 150, $264-273$.

Rawdon, C., Gallagher, P., Glacken, M., Swallow, V., \& Lambert, V. (2019). Parent and adolescent communication with healthcare professionals about Type 1 diabetes management at adolescents' outpatient clinic appointments. Diabet Med, 10, 1 - 12.

Schiaffini, R., Carducci, C., Cianfarani, Mauti, M., \& Nicolais, G. (2019). Post-traumatic Stress Disorder in Children Affected by Type 1 Diabetes and Their Parents. Comprehensive clinical medicine, 1(5), 349 - 353.

Van Gampelaere, C., Luyckx, K., Van Ryckeghem, D., Van der Straaten, S., Lardiaen, J., Goethals, E.R.,Casteels, K., Vanbesien, J., Den Brinker, M., Cools. M., \& Goubert, L. 
Čergelytè - Podgrušiene \& Gudžinskienè, 2020. Needs and Sources of Information on Disease Management for Parents of Children with Diabetes Mellitus

(2019). Mindfulness, worries andparenting in parents of children with type 1 diabetes. Journal of Pediatric Psychology, 44(4), 499-508.

Yilmaz, Y., Polat, S., Yildiz, M., Turgut, S.B., Topal, N., Aydin, B., Onal, H., Tekeli, H., \& Doty, R.L. (2019). Sense of smell and quality of life in children with diabetes mellitus. International journal of pediatric otorchinolaryngology, 123, $43-46$.

Weng, A.T., Zachariae, C., Christensen, K.B., Svensson, J., \& Berg, A.K. (2019). Five-Month Follow-up Shows No Improvement in Dermatological Complications in Children With Type 1 Diabetes Using Continuous Glucose Monitoring Systems and Insulin Pumps. Journal Sage, 16, 1 - 7.

World Health Organization. (2016). World health statistics: Monitoring health for the Sustainable development goals. Switzerland: Geneva.

Žydžiūnaitè, V., \& Sabaliauskas, S. (2017). Kokybiniai tyrimai - principai ir metodai. Vilnius:Vaga.

Žilinskienè, J., Šinkariova, L., \& Perminas, A. (2007). Paauglių, sergančių cukriniu diabetu, depresiškumo ypatybès. Visuomenès sveikata, 43(1), 65 - 69. 